\title{
GASPAR MELCHOR DE JOVELLANOS
}

\author{
Mfmoria para el arreglo de la Policia de los Espectáculos $Y$ \\ Diversiones PÚblicas y SOBRE SU ORIGEN EN ESPAÑa
}

Marfa Clementa Millán

UNED

Esta obra de Jovellanos, como algunas de sus creaciones más importantes, es la respuesta a un encargo específico, realizado en este caso por la Real Academia de la Historia a petición del gobierno'. Su contenido está, por tanto, mediatizado por esta circunstancia, como lo indica el propio autor en su Introducción a la Memoria, «destinada a la instrucción de un expediente gubernativo" ${ }^{2}$. Sin embargo, como sucede también en sus otras producciones de estas características, lo expresado en sus páginas rebasa con mucho el de un mero informe para convertirse en la manifestación de las ideas y principales inquietudes de su autor. Jovellanos realiza una primera redacción de esta obra en $1790^{3}$, cuando bajo el pretexto de un informe sobre las minas de carbón en Asturias es enviado a Gijón, sufriendo

' «La Memoria de Jovellanos fue motivada por un informe que, con fecha 28 de abril de 1786, dirigieron a S.M. los Fiscales del Consejo sobre los abusos introducidos en la sociedad española por la gran difusión de los juegos de azar y otras diversiones privadas». Francisco Aciullar PIÑal, Sevilla y el teatro en el siglo XVIII. Universidad de Oviedo. Cátedra Feijoo. 1974, p. 172. Agradecemos a Francisco AGUILAR PIÑAL la sugerencia de este trabajo.

Esta cita, así como las que aparecen a continuación, pertenece a la edición de José Lage. Madrid, Cátedra, 1986, basada en el texto de Angel DEL Río, Jovellanos. Obras Escogidas. Madrid, Clásicos Castellanos, 1935.

"Su redacción definitiva data de 1796, cuando Jovellanos volvió a reescribir el contenido de su Memoria. Hemos preferido el texto de 1790 por estar menos perfilado por su autor, y por tanto, más acorde con los impulsos que lo motivaron. 
su primer destierro de la corte 4 . Con anterioridad a esa fecha habia escrito como creaciones importantes, Pelayo, de 1769, y El delincuente honrado, estrenada en 1773. La Memoria, redactada a la edad de cuarenta y seis años, es, por tanto, su primera aportación importante a otro tipo de escritos, en los que la intencionalidad literaria está claramente supeditada a otros fines.

Como su título indica esta obra consta de dos partes bien diferenciadas. La primera, destinada «a descubrir el origen de las diversiones públicas en España y su progreso hasta nuestros días, y la segunda a indicar el influjo que aquéllas pueden tener en el bien general y los medios que me parecen más convenientes para conducirlas a tan saludable fin " $^{5}$. La presencia de la primera se explica, como también indica Jovellanos en su Introducción, por el hecho de que «el primer tribunal de la nación», "conociendo cuánta luz puede recibir de los ejemplos de la antigüedad, convida a la Real Academia para que teja su historia»". "El desempeño de tan estimable confianza» le es encargado a Jovellanos, como miembro supernumerario de la misma. Era, por tanto, un escrito de responsabilidad con implicaciones políticas, que venía a responder en el reinado de Carlos IV a la polémica sobre los espectáculos públicos habida en el mandato de su antecesor. Carlos III había

' Su permanencia en Gijón durará siete años, en los cuales escribió, además de esta $M e$ moria, el Informe en el expediente de la ley agraria (que le valió un expediente de la Inquisición en 1796 por el que fue desterrado a Mallorca en 1801) e hizo realidad otro de sus proyectos más anhelados, la creación del Real Instituto Asturiano de Náutica y Mineralogía, en el que Jovellanos pudo ver cumplidas sus ideas sobre la necesidad de una enseñanza en aquellas materias que oponían la "ciencia útil» a la enseñanza escolástica. Su salida de la corte fue motivada fundamentalmente por el cambio ideológico que se produjo en el gobierno con posterioridad a la muerte de Carlos III en 1788 y por ser personaje no grato a la reina María Luisa, esposa de Carlos IV.

${ }^{3}$ Op. cit. p. 74 El título de la Memoria señala explícitamente estos dos apartados fundamentales. Sin embargo el orden en que los indica es opuesto al que aparece en el desarrollo de la obra. El título habla, en primer lugar, del «arreglo de la policía de los espectáculos» y, en segundo término, de su «origen», mientras en la obra de Jovellanos sigue el orden que usará en otras creaciones de estas características como el Informe sobre la ley agraria: exposición de sus antecedentes históricos, descripción del estado actual, y enumeración de los remedios utilizables para mejorar la situación.

" $O p$. cit. p. 73 El buscar posibles modelos en la antigüedad es característico de este siglo, aunque el remontarse en la historia española obedece a otra tendencia de este período, por el que se intenta reconstruir nuestra historia desde nuevas perspectivas. A este objetivo responden obras como la España sagrada del padre Enrique Flórez, el mayor historiógrafo de la época, o el mismo discurso de Jovellanos para la Academia de la Historia, leido en 1779 y titulado Sobre la necesidad de unir al estudio de la legislación el de nuestra historia y antigüedades. Este resurgimiento de la historiografia en el siglo XVIII viene motivado, entre otras causas, por la gran repercusión que tuvo el Essai sur les moeurs de Voltaire, en el que señalaba la diferencia entre el que «creyóse un historiador porque transcribía fechas y narraciones de batallas» y el que «debía enseñarme los derechos de la nación» (Texto citado por Jacqueline Marchand, «Introducción» a Essai sur les moeurs et l'esprit des nations, Paris 1962, pp. 12-13 y recogido por Francois López en su estudio preliminar a Juan Pablo Forner, Discurso sobre el modo de esribir y mejorar la historia de España, Barcelona, Labor, 1973, p. 30). 
prohibido en 1765 la representación de los autos sacramentales, y en 1785, mediante una Pragmática Sanción, impidió la celebración de las corridas de toros. Estas polémicas tenían como fondo la pugna entre dos mentalidades. La tradicional, que convirtió el siglo Xvil español en baluarte de su sistema de valores, y la innovadora, que rechazaba este trasnochado tradicionalismo para sumarse a las nuevas corrientes europeas, a la vez que defendia el mundo del XVI frente al XVII ${ }^{7}$.

Jovellanos satisface en su Memoria estos objetivos, trazando el origen, la historia y el estado actual de los espectáculos en España, al tiempo que da soluciones concretas para el arreglo de su deteriorada situación. Todo ello lo hace movido por una idea central, que también manifiesta en la citada Introducción. La estrecha relación que para él existe entre «el bien general» y «la felicidad individual» y las diversiones públicas. El que sean «vedadas o perseguidas con arbitrarios e importunos reglamentos», o «abandonadas a la casualidad o al capricho de los particulares", incide directamente en la «felicidad pública». Esta idea la desarrolla posteriormente en la Memoria, en la que afirma que «creer que los pueblos pueden ser felices sin diversiones es un absurdo». Un pueblo «cuanto más goce, tanto más amará al Gobierno en que vive, (...) Cuanto más goce, tanto más tendrá que perder (...) En una palabra: aspirará con más ardor a su felicidad, porque estará más seguro de gozarla (...) Siendo pues, éste el primer objeto de todo buen gobierno, ¿no es claro que no debe ser mirado con descuido ni indiferencia? ${ }^{8}$.

7 Jovellanos pertenece a este último grupo, como asi lo declara repetidas veces. En el Elogio de Carlos III, discurso leído ante la Sociedad Económica de Madrid en 1788, hace una entusiasta alabanza del siglo XVı en el que España logró su wápice de grandeza». Estas manifestaciones responden a una visión más amplia por la que se defienden otros aspectos del XVI español, como la religiosidad interior, frente a las manifestaciones religiosas externas del XVII, como los autos sacramentales. Esta fue una de las causas de la gran polémica que tuvo lugar en el xvill sobre estas manifestaciones teatrales y en la que participan numerosos autores. Esta importante polémica ha sido analizada fundamentalmente por René ANDIOC (Sur la quérelle du thêatre au temps de Leandro Férnandez de Moratin, 1970, traducida como Teatro y sociedad en el Madrid del siglo XVIII, Castalia, Madrid 1976).

${ }^{8}$ Op. cit. p. 114. Este planteamiento de gran modernidad se opone a una corriente de pensamiento imperante en su siglo que consideraba las diversiones públicas intrínsecamente ilicitas, especialmente las escénicas. Numerosas obras de este siglo así lo manifiestan, como la titulada Consulta teológica sobre lo ilícito de representar y ver representar las comedias que hoy se hacen en España (1972) del P. Gaspar Díaz, o el Examen teológico sobre los teatros (1766) de Fray Miguel López. (Sobre este aspecto, ver Aguilar PIÑal, Sevilla y el teatro en el siglo XVIII, op. cit. p. 20-21 y ss.). La postura de Jovellanos en este punto se acerca, entre otros ilustrados, a la de Pablo de Olavide a quien conoció en Sevilla, después de su nombramiento como Alcalde del Crimen en esta ciudad. Olavide fue atacado, y posteriormente procesado por la Inquisición, por considerar el baile de máscaras como una diversión uhonesta por sí misma». A pesar de sus intentos de disculpa, Olavide permaneció en prisión dos años, recibiendo la condena inquisitorial doce años antes de que Jovellanos empezara a escribir su Memoria sobre los espectáculos. La importancia del concepto de felicidad en el xvIII español ha sido analizado, entre otros autores, por José Antonio Maravall en «La idea de felicidad 
Este convencimiento es el principio motor de Jovellanos al escribir esta Memorid, siendo consciente de que «acaso cuanto he dicho será oído con escándalo por los que miran estos objetos como frívolos e indignos de la magistratura. ¿Puede nacer este desdén de otra causa (...) que no de ver la relación que hay entre las diversiones y la felicidad pública, o de creer mal empleada la autoridad cuando labra el contento de los ciudadanos?»" Para Jovellanos el objetivo esencial de un gobierno es procurar la felicidad pública, no dictar unas leyes que impidan el contento general ${ }^{10}$. Para que se dé esta situación son necesarias la libertad y la alegria, porque «entre varas y bayonetas la libertad se amedranta y la tímida e inocente alegría huye y desaparece»... «La libertad y la alegría de los pueblos están más distantes del desorden que la sujeción y la tristeza»... «El estado de libertad es una situación de paz, de comodidad y de alegria; el de sujección lo es de agitación, de violencia y disgusto" ${ }^{11}$. De ahí la importancia de una correcta policía de los espectáculos, que permita esta alegría pública, pero convenientemente encauzada. "Su vigilancia debería parecerse a la del Ser Supremo; ser cierta y continua, pero invisible (...) de otro modo el respetable aparato de la justicia se convertiria en instrumento de opresión».

La labor de escribir esta Memoria encierra para su autor una gran responsabilidad, ya que debe trazar las vías que permitan este estado de libertad y alegría del que depende «el consuelo y acaso la felicidad de la nación». Jovellanos pide al final de su escrito que la Real Academia «no desaproveche esta ocasión, tal vez única», una vez que el «Augusto Carlos IV" ha vuelto "su atención a un objeto tan descuidado antes de ahora" y de tanta repercusión en el «bien general». Este arreglo de los espectáculos

en el programa de la Ilustración», Mélanges offerts à Charles Vicent Aubrun, París 1975, pp. 425-462. Sobre este aspecto ver asimismo Robert MAUzI, L'idée du bonheur au XVIII siècle. Paris, Colin, 1969, cap. V.

Op. cit., p. 129.

10 El papel de la ley en la sociedad constituye para Jovellanos un objeto de reflexión, además de formar el centro de su actividad laboral desde que en 1767 abandonara su carrera eclesiástica para dedicarse a la Magistratura. Este es uno de los temas fundamentales de El delincuente honrado, su segunda obra teatral, escrita en Sevilla para participar en un concurso literario organizado en las renombradas tertulias de Olavide. En esta pieza el autor se mueve en la línea del jurista Cecare Bonesana Beccaria, marqués de Beccaria, como parece indicarlo la transcripción de un párrafo de su obra Dei delitti e delle pene (1764) al final de la pieza. Esta obra de Beccaria tuvo una enorme repercusión en su tiempo, contribuyendo a reformar las duras leyes penales. La primera traducción española es la realizada por Juan Antonio de las Casas en 1774, el mismo año en que Jovellanos se traslada a Sevilla, y cuatro años antes de la condena inquisitorial de Olavide. Jovellanos en su pieza teatral condena también la dureza de las leyes en nombre de la humanidad y la razón, propios del pensamiento ilustrado. Esta «humanidad» defendida por Jovellanos aparece también en la Memoria sobre los espectáculos, en la que se muestra especialmente sensible a la necesidad de alegría del corazón humano frente a aquellos que quieren abolir las diversiones públicas a través de leyes injustas.

"Op. cit., pp. 122, 121 y 120, respectivamente. 
debe hacerse con mucho tiento, sin «destruir las diversiones a fuerza de autoridad», pero sin «abandonarlas a una ciega y desesperada licencia». En este término medio se mueve Jovellanos, que señala una y otra vez la importancia de la alegría en la vida pública. «Llena nuestra vida de tantas amarguras, ¿qué hombre sensible no se complacerá en endulzar algunos de sus momentos?": ${ }^{12}$. La conexión que establece entre alegría y felicidad pública, y consecuentemente, entre diversión y bien general, diferencia su postura de la de otros ilustrados, como la del Padre Feijoo, que ataca la costumbre de las romerías, defendidas por Jovellanos tanto en su Memoria como en la Carta VIII a Antonio Ponz en la que dice:

«Sé que entre los reprobadores de las romerias se encuentra el sabio Feijoo; pero ¿me atraveré a decir a usted lo que siento de su declamación? ¿Y por qué no? Léala, y si comparando su estilo pedantesco, su mala lógica, y sus frívolos argumentos con sus otros escritos, no juzgase usted, como yo, que aquel discurso es un trozo de sermón trabajado en los primeros años, cuando no estaba aún ilustrada su razón crítica, ni formado su gusto, téngame usted por temerarion' ${ }^{13}$.

Esta actitud tolerante es la que mantiene Jovellanos en toda su Memoria, tanto al emitir un juicio sobre el origen y estado actual de los espectáculos, como al tratar de sentar las bases para su reforma. La importancia que concede a la felicidad pública le lleva a mantener este talante, a pesar de ser temas vinculados al bien y virtud generales ${ }^{14}$. Cuando en la primera parte

${ }^{12}$ Op. cit., pp. 122, 145, 111 y 129, respectivamente.

${ }^{13}$ Ed. de José Caso González, Gaspar Melchor de Jovellanos. Obras en prosa, Madrid, Castalia, 1969, p. 153. Las obras de Feijoo no se encontraban entre la nutrida biblioteca de Jovellanos en Sevilla, que, sin embargo, contenia numerosas creaciones de otros autores del XVIII, según se puede ver por la descripción de sus títulos (Francisco AguILAR PIÑal, La biblioteca de Jovellanos (1778), Madrid, Instituto "Miguel de Cervantes", C.S.I.C., 1984). Las cartas a Ponz presentan numerosos puntos en común con las ideas expresadas por Jovellanos en la Memoria sobre los espectáculos, especialmente en lo referente a las necesidades del pueblo y a la especial sensibilidad del autor ante sus tradiciones.

${ }^{14}$ Esta actitud tolerante de Jovellanos tiene puntos de semejanza con la mantenida por Pablo de Olavide en Sevilla, ciudad en la que ocupó el cargo de Asistente y Superintendente de las Nuevas Poblaciones de Sierra Morena. El limeño Olavide dirigia la vida cultural sevillana, y en sus refinados salones del Alcázar se comentaban las nuevas tendencias del pensamiento europeo. Estas tertulias parecieron influir poderosamente en el joven Gaspar de Jovellanos que entonces contaba veintitrés años. Allí profundizó en el conocimiento de la lengua inglesa, traduciendo el Canto I del Paraiso perdido de Milton, y escribió sus primeras obras literarias, Pelayo y El delincuente honrado. Sobre la repercusión de Olavide en el mundo ilustrado, véase, Marcelin Defourneaux, Pablo de Olavide, el afrancesado, México 1965, y Francisco Aguilar Piñal, La Sevilla de Olavide. 1767-1778, Sevilla 1966, y Sevilla y el teatro en el siglo $X V I I I$, op. cit. 
de este escrito trata sobre el «Origen general de las diversiones y espectáculos en España» y sobre la "Historia particular de los espectáculos», los únicos que rechaza más abiertamente son los toros y parte de los juegos escénicos. El resto de las diversiones: caza, romerias, juegos privados, torneos, fiestas "palacianas» ${ }^{15}$ y juegos escénicos (debidamente entendidos bajo el prisma ilustrado) no son atacadas por el autor. Por el contrario, destaca en ellas lo que pudiesen tener de «brillante colorido», de espectáculo en definitiva, que si «no cubrió del todo su fiereza, por lo menos la hizo más agradable»:

«En sus fiestas de monte y sala, en sus torneos y justas y juegos de caña y de sortija, y hasta en las luchas de toros; y que al fin reguló el ceremonial y la pompa, y la publicidad y el entusiasmo con que llegaron a celebrarse estos espectáculos»" ${ }^{16}$.

El espíritu de Jovellanos parece vibrar ante el boato externo que ofrecían estas diversiones, especialmente las que pertenecen al mundo medieval. Dedica particular atención a los torneos ${ }^{17}$, que describe minuciosamente, recogiendo el «entusiasmo y la palpitación que herviría en sus pechos, aguijados por los más poderosos incentivos del corazón humano, el amor y la gloria». Siente su desaparición como una pérdida, y los compara con los «ruines, exclusivas y compradas fiestas» actuales, criticando a la nobleza

is Este vocablo usado por Jovellanos es considerado por el Diccionario de Autoridades como palabra anticuada para ser utilizada en el siglo xvill. En la Edad Media tenía el significado de claro, elevado de estilo, y en sentido connotativo, el de cortesano. Jovellanos lo utiliza en vez del término actual de palaciegas. Agradecemos a Rafael Cano esta información.

${ }^{16}$ Op. cit., p. 83.

17 La atracción por lo medieval es una característica del pensamiento de Jovellanos que se manifiesta en otras obras, como en sus Memorias histórico-artísticas de arquitectura (1802) al tratar del castillo de Bellver, en el que estuvo encarcelado durante su destierro en Mallorca. Tanto en esta obra como en su Memoria sobre los espectáculos el autor parece oponer la prosaica y negativa realidad de su tiempo al esplendor de las cortes medievales. Es interesante notar que cada una de estas obras coincide con un destierro de Jovellanos, por lo que no es extraño que el autor buscase la evasión a través de lo medieval, vía que posteriormente utilizarían los románticos. Este interés de Jovellanos por lo medieval aparece explícitamente expresado en el Apéndice que añade al contenido de la Memoria, recogiendo Las ordenanzas del torneo y de la justa que dio Alfonxo XI al instituir la Orden de Caballería de la Banda a las que el autor hace referencia en su Memoria al tratar sobre los torneos y otras fiestas medievales. 
por no haber sabido mejorar aquel espectáculo ${ }^{18}$. Al igual que sucedia con las romerías, muestra su desacuerdo con aquellos que critican este entretenimiento, perdiendo de vista las costumbres y los tiempos, y «no saben descubrir aquel secreto vínculo que tan poderosamente los enlaza» ${ }^{19}$. Como justificación última de este espectáculo traduce las palabras de Ferguson en su ensayo sobre la historia de la sociedad civil, en que afirma que el hombre «nacido para vivir poco, parece que hasta sus diversiones le acercan al sepulcro" ${ }^{20}$.

Una actitud semejante muestra el autor ante las «fiestas palacianas», a las que considera «el gran paso dado (...) hacia la cultura del espíritu (...) haciendo a los hombres más sociables, más sensibles y cómo poco a poco los fueron guiando hacia los tranquilos y honestos placeres de la buena compañía ${ }^{21}$. Jovellanos se siente igualmente entusiasmado al recrear el ambiente de aquellas fiestas, a las que considera «imperio de la hermosura» $y$ de las "sublimes gracias del ingenio». Muestra una visión idealizada de sus ambientes, en los que "era todo magnífico»" contrastándolos implícitamente con los entretenimientos de la nobleza de su tiempo. Su actitud cambia, sin embargo, al hablar de los festejos taurinos y de los juegos escénicos, espectáculos que habían suscitado las ya citadas polémicas. Defiende «el celo ilustrado del piadoso Carlos III», que proscribió las corridas de toros, para "consuelo de los buenos espíritus" y "sentimiento de los que

18 Esta es la primera critica que realiza Jovellanos en esta obra contra la nobleza de su tiempo, que aparece igualmente en otras creaciones del autor, como sus Sátiras a Arnesto, especialmente en la segunda, publicada anónima en El Censor el 31 de mayo de 1787, tres años antes de escribir la Memoria sobre los espectáculos. En ella Jovellanos arremete contra el estado actual de la nobleza, aunque no como clase social, sino por no tener el grado de dignidad y distinción que, en su opinión, le corresponde. Su crítica a esta clase social en la Memoria sobre los espectáculos no es radical, diferenciándose de otros autores de su época como el abate Marchena en su manifiesto $A$ la nación española o León de Arroyal en su escrito irónico. Oración apologética en defensa del estado floreciente de España. Sobre este aspecto ver Antonio Elorza, La ideologia liberal en la llustración española, Madrid, Tecnos, 1970; y Pan y toros y otros papeles sediciosos de fines del siglo XVIII, Madrid 1971; así como J. A. MARAVALL, "Las tendencias de reforma politica en el siglo XVIII español», Revista de Occidente, julio, 1967.

${ }^{19}$ Op. cit., pp. 93-94.

${ }^{20}$ Esta cita del escrito de Ferguson An Essay on the History of Civil Society, traducida directamente del inglés por Jovellanos que prefería leer en idioma original, demuestra una vez más esa faceta humanista del autor. La elección y reproducción de estas palabras en una obra como la Memoria sobre los espectáculos pone de manifiesto la sensibilidad del autor, que hace suyas reflexiones de este tipo en un escrito presumiblemente objetivo como este informe.

${ }^{21}$ Op. cit., p. 100.

${ }^{22}$ Op. cit., p. 99 . La positiva visión de Jovellanos sobre las fiestas medievales es semejante a la adoptada por el autor al hablar de las diversiones del pueblo, en las que no ve defecto ni peligro alguno para la corrupción de las costumbres. En este aspecto se ha señalado la influencia de Rousseau, mientras que en su pasión por lo medieval se le ha llegado a comparar con Chateaubriand, en su obra Génie du Christianisme (1802) (José Miguel Caso González. "La prosa en el siglo XVIII", Historia de la Literatura Española, tomo III, Madrid. Taurus, 1982, p. 129). 
juzgan de las cosas por meras apariencias». No considera esta fiesta como nacional, ya que de la población «apenas la centésima parte había visto alguna vez este espectáculo. ¿Cómo, pues se ha pretendido darle el título de diversión nacional?» Tampoco lo cree exponente del «valor y bizarría española» presentable a «la misma Europa»" ${ }^{23}$. Sin embargo, afirma que es un «arte capaz de recibir todavía mayor perfección si mereciese más aprecio», aunque alaba la decisión del Gobierno que «ha prohibido justamente este espectáculo» ${ }^{24}$.

También muestra Jovellanos su conformidad con la abolición de los autos sacramentales, a los que califica de «supersticiosa costumbre»" ${ }^{25}$. Porque el velo de piedad que los recomendó en su origen no bastaba ya a cubrir, en tiempos de más ilustración, las necedades e indecencias que malos poetas y peores farsantes introdujeron en ellos, con tanto desdoro de la santidad de su objeto como de la dignidad de los cuerpos que los veían y toleraban». Esta opinión ilustrada comienza con su condena al teatro de Lope de Vega, «en que la ignorancia vio la suma de su perfección» y «la sana crítica de las semillas de la depravación y la ruina de nuestra escena» ${ }^{26}$. Sin embargo, defiende los dramas de Calderón y Moreto, que «son hoy, a pesar de sus defectos, nuestra delicia, y probablemente lo serán mientras no desdeñemos la voz halagüeña de las musas $»^{27}$. Este último juicio del autor sobre uno de los máximos dramaturgos del XVII es un exponente más de la actitud señalada en Jovellanos ante los espectáculos públicos. Mantiene una postura ilustrada y partidaria de las prohibiciones de Carlos III, en cuyo reinado "ganó algo la música y mucho la decoración» del teatro, «rayando más de una vez la esperanza de que reformasen las demás partes de este espec-

${ }^{23}$ Op. cit., p. 97.

${ }^{24}$ Op. cit., pp. 97 y 98, respectivamente. En estas dos frases está contenida la posición sincrética de Jovellanos, que intenta conciliar la prohibición de Carlos III como medida ilustrada con su inclinación a apreciar la estética del espectáculo. El resultado es un término medio, en el que defiende la orden del Gobierno, convertida casi en símbolo para los ilustrados, a la vez que sugiere la necesidad de perfeccionar este espectáculo.

${ }_{25}$ Para apoyar su postura cita a Cervantes (capitulo XII de la primera parte del Quijote). Jovellanos demuestra en su Memoria ser un gran conocedor de Cervantes, a quien pone como modelo frente al «depravado» teatro de Lope de Vega. Esta defensa no sólo obedece a razones de reglamentación neoclásica, sino al renacer que hay en este siglo de la figura cervantina, por ser éste el principal escritor al que se debe mirar para intentar trazar de nuevo nuestra historia literaria. Gregorio Mayáns y Siscar escribió en 1737 la primera biografia de Cervantes, que podría considerarse como el origen del cervantismo en España.

${ }^{26}$ Op. cit., p. 108.

${ }^{27}$ Op. cit., p. 110. Esta actitud parece ser un rasgo genuino de la personalidad de Jovellanos, como ha señalado Ângel del Río, oponiéndose a aquellas críticas que trataron de encasillar al autor del Xvill en una de "Las dos Españas". De este modo "se perdió de vista el rasgo más saliente: el eclecticismo de su obra, el esfuerzo verdaderamente ejemplar por armonizar las corrientes contradictorias que influyeron en su pensamiento y formaron su sensibilidad", «Introducción», op. cit., p. 10. 
táculo ${ }^{28}$. Sin embargo, su posición se ve matizada por la importancia que le concede a la felicidad pública, lo que le lleva a denunciar que en el mandato de este rey se fueran "cerrando los teatros de las provincias, y el espectáculo que las había entretenido casi por el espacio de tres siglos vino, al fin, a formar la diversión de tres solas capitales $)^{29}$.

Esta misma actitud se refleja en las medidas que propone en la segunda parte de su Memoria para «el arreglo de los espectáculos». Tanto para el pueblo que trabaja, que «no ha menester que el Gobierno le divierta, pero sí que le deje divertirse» ${ }^{30}$, como para las "clases pudientes», defiende la importancia de la diversión pública, si bien diferencia entre ésta y los espectáculos, destinados a los nobles, pero no al pueblo ${ }^{31}$. De ahí, el cierto matiz negativo con que adorna estos últimos, dirigidos a aquéllos de «vida blanda y regalada", "cuyo principal objeto es pasar alegremente una buena parte del día", y a los que "una buena educación sería capaz de sugerir muchos medios de emplear útil y agradablemente el tiempo sin necesidad de espectáculos ${ }^{32}$. Sin embargo, a pesar de esta crítica ilustrada a la nobleza a través del tema de los espectáculos, Jovellanos señala una serie de «re-

${ }^{28}$ Op. cit., p. 111 .

${ }^{29}$ Op. cit., p. 42. Sorprende ver en Jovellanos estas palabras sobre Carlos III, que encierran una crítica a la labor de este rey en materia de espectáculos. Su contenido contrasta con el beneplácito dado anteriormente a las prohibiciones que llevó a cabo, y también con su Elogio de Carlos III, leido dos años antes con un mes de antelación a la muerte del monarca. En la Memoria sobre los espectáculos parece darle mayor significación a su sucesor Carlos IV, a pesar de que los infortunios de Jovellanos empezaron con su reinado. La causa podría radicar en la gran importancia que concede el autor al arreglo de esta policía para la «enseñanza civil» de la sociedad.

${ }^{30}$ Op. cit., p. 117.

"Los espectáculos, según Jovellanos, están dirigidos a la aristocracia. El pueblo y la nobleza son compartimentos estancos para el autor, que afirma la bondad natural del primero, siempre que no intente entrometerse en unas manifestaciones sociales que no le correspondan como el teatro o los bailes de máscaras. Jovellanos, como Olavide, tiene una concepción aristocrática de estas diversiones, a las que intentó sacar del aplebeyamiento que gozaban en la época y hacer de ellas unos entretenimientos selectos, dirigidos a una clase social que también debía ser remozada, como la nobleza. Estos intentos provocaron el proceso inquisitorial de Olavide, a la vez que contribuyeron a la desgracia que persiguió a Jovellanos en la corte hasta su largo destierro en Mallorca.

32 Estas palabras de Jovellanos, que responden claramente a un pensamiento ilustrado, tienen en este autor una particular significación dada su especial preocupación por el problema educativo. En la falta o enfoque erróneo de la educación, tanto científica como civil, está para Jovellanos la base de la calamitosa situación de la sociedad española. Su reforma es, por tanto, de absoluta prioridad en ambos campos: científica (reforma de las universidades y planes de estudio) y civil (arreglo de los espectáculos). Estas ideas de Jovellanos expresadas en la Memoria sobre los espectáculos están estrechamente vinculadas al eje central de su pensamiento reformador, lo que explica la vehemencia con que el autor las quiere comunicar. Jovellanos volverá a insistir en la importancia de una educación para la nobleza en su escrito de 1798 , Plan para la educación de la nobleza y clases pudientes españolas, en el que determina los distintos aspectos de esta formación. 
medios» que demuestran una actitud positiva ante la diversión pública como elemento esencial de la felicidad general. Se opone a las «leyes injustas» que han prohibido ciertas diversiones para el pueblo que trabaja, como «el uso de los palos» en Asturias, o las romerías antes citadas, denunciando «el furor de mandar, y alguna vez la codicia de los jueces», que «han extendido hasta las más ruines aldeas reglamentos que apenas pudiera exigir la confusión de una corte»" ${ }^{33}$. Esta "mala policía» emanada de unas leyes erróneas, ha llevado a una situación en que «la mayor parte de los pueblos de España no se divierten en manera alguna ${ }^{34}$ :

"Si algunas personas salen de sus casas, no parece sino que el tedio y la ociosidad las echan de ellas, y los arrastran al ejido, al humilladero, a la plaza o al pórtico de la iglesia, donde embozados en sus capas o al arrimo de alguna esquina, o sentadas o vagando acá y acullá, sin objeto ni propósito determinado, pasan tristemente las horas y las tardes enteras sin espaciarse ni divertirse. Y si a esto se añade la aridez e inmundicia de los lugares, la pobreza y desaliño de sus vecinos, el aire triste y silencioso, la pereza y la falta de unión y movimiento que se nota en todas partes, ¿quién será el que no se sorprenda y entristezca a vista de tan raro fenómeno? $)^{35}$.

Esta situación es la que intenta paliar Jovellanos mediante las leyes que pudieran emanar de su Memoria, tratando igualmente de ofrecer a la nobleza unas diversiones «inocentes y públicas, para separarlas de los placeres oscuros y perniciosos». Con estos entretenimientos se lograría otro objetivo esencial para el Jovellanos hombre de estado y defensor de su tierra natal. $\mathrm{El}$ «retener a los nobles en sus provincias y evitar esta funesta tendencia

${ }^{33}$ Op. cit., p. 119

34 Op. cit., p. 118. Para Jovellanos las leyes son la fuente fundamental de la que emana una buena o mala policia de espectáculos. Por ello, la historia de las diversiones en España que traza en su Memoria está basada esencialmente en leyes que fueron promulgadas a tal efecto. El mismo autor en una serie de notas a pie de página indica las fuentes de las que procede su información, aunque la mayor parte de los datos derivan de las Memorias sobre los teatros, escritas por don José Antonio de Armona, corregidor de Madrid, «que nos confió para extractarlo este precioso manuscrito". Otra parte de la información procede de la obra de Francisco Antonio de Bances y LoPez CANDAMo, Teatro de los teatros de los pasados y presentes siglos. Sin embargo, Jovellanos cita cada una de las fuentes que utiliza, dando con ello un rigor científico a su escrito.

${ }^{35}$ Op. cit., p. 118. Esta visión de España que presenta Jovellanos es semejante a la que ofrece León DE ARROYAL en la Oración apologética en defensa del estado floreciente de España (1793-96) en la que dice: «Ha ofrecido a mi vista una España niña y débil, sin población, sin industria, sin riqueza, sin espiritu patriótico, $y$ aún sin gobierno conocido" (citado por Antonio Elorza, "Pan y Toros" y otros papeles sediciosos de fines del siglo XVIII, Madrid 1791). 
que llama continuamente al centro» ${ }^{36}$. Los que vienen a la corte, «sin destino no vinieron en busca de otra cosa que de la libertad y la diversión que no hay en sus domicilios». Esto lleva a «despoblar y empobrecer las provincias» y «acumular y sepultar en pocos puntos la población y la opulencia del Estado, con ruina de su agricultura, industria, tráfico interior y aún de sus costumbres». Para evitar esta situación propone una serie de entretenimientos, como maestranzas, academias dramáticas, saraos públicos, bailes de máscaras, casas de conversación ${ }^{37}$, juegos de pelota, y representaciones teatrales, de los que algunos, o se estaban perdiendo como las maestranzas, herencia de «nuestros antiguos caballeros»" ${ }^{38}$, o habian sido prohibidos, como las máscaras, que quizá «fuera menos arriesgado arregladas», «como sucede en Italia, y señaladamente en Turín ${ }^{39}$. Jovellanos toma como punto de referencia para desarrollar algunos aspectos de su reforma el mundo italiano, como la Corte de Parma para la instauración de las academias dramáticas, «institución digna de ser imitada ${ }^{40}$. Califica el teatro de «el primero y más recomendado de todos los espectáculos) $)^{41}$, aunque en él deben reunirse "estos dos grandes objetivos: la instrucción y la diversión pública». "La más santa y sabia policía de un gobierno» es la que sepa realizarlos, y «si ningún pueblo de la tierra, antiguo ni moderno, la ha con-

36 Op. cit. p. 124. Este es otro de los objetivos fundamentales de la Memoria, que tiene una función concreta que cumplir en el gobierno de la Nación: el intentar que las provincias no pierdan el esplendor que les proporciona la aristocracia, lo que a la vez favorece el bien quehacer del gobierno central. Jovellanos defiende los intereses de su tierra natal en numerosos escritos, especialmente en los que están redactados, como esta Memoria, en tierras asturianas. Algunas de las Cartas a Ponz, el Informe sobre la ley agraria, y los relacionados con el Instituto de Náutica y Mineralogia, son buena muestra de ello.

${ }_{37}$ Jovellanos da gran importancia en esta Memoria a las diversiones que entrañan un intercambio de ideas, como estas casas de conversación o las fiestas palaciegas medievales, que «engrandecen el espíritu». El mismo será asiduo a este tipo de diversiones, acudiendo en Sevilla a la tertulia de Olavide y en Madrid a la de Campomanes. En ambas tratará con lo más destacado de la intelectualidad y aristocracia de su tiempo.

${ }_{38}$ Op. cit. p. 125 . El autor intenta revivir, a través de las medidas que propone en esta Memoria, aquellos aspectos del mundo medieval que puedan contribuir con su aplicación al engrandecimiento de la nobleza de la época. El pensamiento de Jovellanos sobre la nobleza encierra, por tanto, una actitud crítica y a la vez, una ensoñación evocadora de glorias pasadas, que diferencia su postura de la de otros ilustrados de su tiempo, centrados casi exclusivamente en la crítica antes mencionada.

${ }_{39}$ Op. cit. p. 127. Como el Conde de Aranda y Olavide, Jovellanos propone la instauración de los bailes de máscaras. «Una docena de estos bailes, dados entre Navidad y Carnaval» (p.127), en los que «puede haber ciertamente en esta diversión, como en todas, algunos excesos y peligros pero ninguno inaccesible al desvelo de una prudente policia» (p. 128).

${ }_{40}$ Op. cit. p. 126. «Esta academia propone asuntos para la composición de buenos dramas, los juzga (...), premia los ingenios (...), y perfecciona (...) el arte de la declamación». Jovellanos las considera una ocupación perfecta para la nobleza.

${ }^{41}$ Op. cit. p. 130. 
seguido hasta ahora, es porque en ninguno ha sido el teatro el objeto de la legislación, por lo menos en este sentidon" ${ }^{42}$.

Jovellanos espera que esta legislación pueda surgir de las medidas que propone para la reforma del teatro, que «debe empezar por el destierro de casi todos los dramas». No sólo de los realizados por "hambrientos e ignorantes poetucos», sino también de aquéllos «justamente celebrados entre nosotros, que algún día sirvieron de modelo a otras naciones, y que la porción más cuerda e ilustrada de la nuestra ha visto siempre, y ve todavía, con entusiasmo y delicia» ${ }^{43}$. No obstante, estos dramas, «mirados a la luz de los preceptos y principalmente a la de la sana razón, están plagados de vicios y defectos que la moral y la política no pueden tolerar ${ }^{44}$. Para el autor los principales requisitos que debe cumplir una pieza teatral no son los literarios, ya que entonces aceptaría plenamente las creaciones del siglo XVII, según afirmaba con anterioridad. Lo importante es que sirva de ejemplo, "de reverencia al Ser Supremo y a la religión de nuestros padres; amor a la patria, al Soberano y a la Constitución; de respeto a las jerarquias, a las leyes y a los depositarios de la autoridad; de felicidad conyugal, de amor paterno, (...), hombres heroicos y esforzados, amantes del bien públicon, a la vez que ridiculice «los demás vicios y extravagancias que turban y afligen la sociedad»... "Todos los malos hábitos en que caen los hombres cuando salen del sendero de la virtud, del honor y de la cortesía por entregarse a sus pasiones y caprichos»... "Un teatro tal, después de entretener honesta y agradablemente a los espectadores, iría también formando su corazón y cultivando su espíritu; es decir, que iría mejorando la educación de la nobleza y rica juventud, que de ordinario le frecuenta. En este sentido su reforma parece absolutamente ncesaria» ${ }^{45}$. El teatro es para Jovellanos una

42 Op. cit. p. 130. El autor cifra nuevamente toda su esperanza en una correcta legislación, destacando el papel esencial de las leyes en la vida pública.

${ }^{4}$ Op. cit. p. 132. El subrayado es nuestro.

4 Op. cit. p. 132. «En ellos, se ven pintadas con el colorido más deleitable las solicitudes más inhonestas; los engaños, los artificios, las perfidias; fugas de doncellas, escalamientos de casas nobles, resistencias a la justicia, duelos y desafios temerarios (...)». Esta visión del teatro responde plenamente al pensamiento del xviII, en el que la pieza teatral debe servir de ejemplo y adecuarse a la realidad, sin evadir al espectador de su circunstancia inmediata como en el teatro del XVII.

45 Op. cit. p. 133. La acción educadora del teatro fue señalada por numerosos escritores del xviII, como Campomanes, Olavide, Forner, Foronda, Clavijo, Nicolás Fernández de Moratín y Luzán, entre otros. Luzán en el «Libro Tercero» de La Poética llama la atención sobre «la tolerancia o descuido del gobierno en un punto tan esencial como el de los teatros, pues permitió y aún permite ahora se representen al ínfimo vulgo como heroicidades los delitos atroces» (ed. de Russell P. Sebold, Barcelona 1977, p. 389). Asimismo Nicolás Fernández de Moratín afirma que udespués del púlpito que es la cátedra del Espíritu Santo, no hay escuela para enseñarnos más a propósito que el teatro, pero está hoy día desatinadamente corrompidon (Emilio COTARELO, Bibliografia de las controversias, sobre la licitud del teatro en España (Madrid 1904, pp. 471-72). Este aspecto tan señalado del teatro del XVIII ha sido estudiado, entre 
de las principales vías para educar a las minorías acomodadas, dándoles una "enseñanza civil», diferente de la «enseñanza científica». El camino no es despojar a esta clase social «de su elevación, de su magnanimidad, de su esfuerzo y de tantas dotes como la hacian recomendable ${ }^{46}$, sino proporcionarle una educación. "Y pues que los jóvenes ricos han de frecuentar el teatro, $i$ por qué en vez de corromperlos con monstruosas acciones o ridículas bufonadas, no los instruiremos con máximas puras y sublimes y con ilustres y virtuosos ejemplos».

El autor quiere revitalizar la escena, despojarla de todo lo que pudiera haber en ella de plebeyo para convertirla en un espectáculo elevado, propio de la aristocracia a la que va dirigido. Para conseguirlo propone suprimir de los escenarios «las antiguas comedias», "casi todos los entremeses», «los modernos sainetes y tonadillas», además de "los títeres y matachines», «los pallazos»" ${ }^{47}$, "arlequines», "graciosos del baile de cuerda», "linternas mágicas», "totilimundis» y "don Cristóbal de Polichinela» con sus «indecentes groserías $\aleph^{48}$. También cree necesario mejorar el contenido de los dramas, sus representaciones (actores, decoración, música, ballet) asi como la dirección y gobierno de los teatros ${ }^{49}$. Para solucionar cada uno de estos aspectos establece medidas concretas: la creación de un concurso nacional, con «dos premios anuales de cien doblones y una medalla de oro», para «lograr en poco tiempo algunos buenos dramas $)^{50}$, que serían juzgados por la Real Academia de la Lengua. No se permitiría representacion alguna sin la aprobación académica ${ }^{51}$, y para mejorar su puesta en escena se buscarían maes-

otros autores, por José Antonio Maravall, en «La función educadora del teatro en el siglo de la Ilustración», Estudios dedicados a Juan Peset Aleixandre, II, Valencia 1982.

${ }^{46} O p$. cit. p. 135 . Es interesante destacar que esta Memoria está escrita un año después de estallar la Revolución francesa en 1789. Sin embargo, Jovellanos, a pesar de sus ideas innovadoras, defiende en este punto el antiguo régimen y la nobleza como clase social.

47 Según el Diccionario de Corominas, el término actual de «payaso» aparece recogido por vez primera en la edición del Diccionario de la Lengua Española de la Real Academia Española de 1832. El vocablo utilizado por Jovellanos no está señalado, y su origen parece incierto, ya que no procede directamente ni del francés (paillasse) ni del italiano (pagliaccio). Agradecemos a Rafael Cano esta información.

48 Op. cit. p. 135.

49 En considerar el teatro como hecho teatral y no exclusivamente como texto literario también se podría establecer un paralelismo entre Jovellanos y Olavide, que con una gran visión de futuro crea en Sevilla una escuela de actores que posteriormente surtiría a los teatros madrileños de la corte (AguILAR PIÑAL; Sevilla y el teatro del siglo XVIII, p. 103). Las actitudes de Jovellanos y Olavide en materia de espectáculos parecen ir parejas como expresión en ambos autores de un innovador modo de pensar. Sin embargo, en Jovellanos aparece un matiz adicional que no es tan evidente en Olavide y que refleja la dimensión de hombre de estado de Jovellanos: la directa relación que establece entre policía de espectáculos y buen desarrollo de las tareas de gobierno.

So Op. cil. p. 136.

51 Esta medida garantizaba la adecuación de los dramas a los preceptos ilustrados, lo que 
tros extranjeros, pues considera que «la declamación es un arte» ${ }^{52}$. También se enviarian «jóvenes a viajar e instruirse fuera del reino", y se crearía una «escuela práctica para la educación de nuestros comediantes» ${ }^{53}$ mediante una serie de decretos de gran modernidad. La profesión de actor se intentaría fomentar igualmente con la institución de otras medidas, como la creación de otros dos premios anuales, distinciones de honor, colocaciones por servicios prestados, etc., con el fin de whonrar y mejorar esta profesión, hoy tan atrasada y envilecida entre nosotros $)^{54}$. La dirección y gobierno de los teatros seria encargada a las Academias Dramáticas, que intentarian poner fin al desorden actual, debido fundamentalmente a la baja calidad de las obras, $y$ al tener que estar tres horas de pie la mayor parte de los espectadores. Para llevar a cabo una "reforma tan radical y completa» serían necesarios "grandes fondos", que procederían de lo que se recaudase en los propios teatros. "La pobreza de nuestros mejores teatros» proviene de "haberse hecho de ellos un objeto de contribución", pues, "¿qué relación hay entre los hospitales de Madrid, los frailes de San Juan de Dios, los niños desamparados, la secretaría del corregimiento y los tres coliseos? Sin embargo, he aquí los partícipes de una buena porción de sus productos ${ }^{55}$.

Jovellanos pretende hacer de la reforma del teatro y de las diversiones públicas un objetivo primordial para la Nación del que en gran medida depende el «anhelo» y la «felicidad» públicas ${ }^{56}$. Para lograrlo no deben es-

en definitiva era una forma de censura implicita que dirigia la politica teatral según los mecanismos del despotismo ilustrado.

s2 Op. cit. p. 137.

s3 Op. cit. p. 138. Estos proyectos ponen de manifiesto la abierta mentalidad de Jovellanos. Muchos de ellos no se verían cumplidos hasta entrado el siglo XX cuando, gracias a los aires reformadores de la Institución Libre de Enseñanza y la Junta para Ampliación de Estudios, muchos jóvenes españoles salieron a formarse al extranjero, y el teatro se vio influenciado por intentos innovadores, creándose varias escuelas de teatro, como las establecidas por Cipriano Rivas Cherif en los años veinte. Tanto en el Xvill como en el $\mathrm{xX}$ estos proyectos surgieron de un afán renovador, ligados en ambos casos a lo nuevo que en aquellos momentos se estaba realizando en el resto de Europa. Sobre la faceta educadora de Jovellanos, ver J. H. R. PoLT, «Jovellanos y la educación», Cuadernos de la Cátedra Feijoo, II, N. ${ }^{\circ} 18$, pp. 315-338.

$\$$ Op. cit. p. 139.

ss Op. cit. p. 143. Jovellanos quiere hacer del teatro un mundo autónomo, subvencionado por sus propios ingresos y cuidado en sus aspectos más genuinamente teatrales. En la decoración, la música y el baile, España debe ponerse a la altura de otros paises europeos, sin que se hagan «insípidas e incoherentes imitaciones», y desterrar del escenario «los manolos y verduleras». La "estrecha e incómoda figura de los coliseos», el "gusto bárbaro y riberesco de arquitectura y perspectiva en sus telones y bastidores», el «desaliño de los trajes» debe desaparecer (p. 140). Si en Madrid «apenas hemos llegado a conocer, no digo la ostentación y la magnificencia, más aún la decencia y regularidad, ¿qué será de los demás teatros de España?» (p. 139).

s6 La Nación para Jovellanos, al igual que para la mayor parte de los autores del XviII, es un tema esencial que preocupaba hondamente a los ilustrados. Todo se proyecta y se piensa 
catimarse fondos, ya que de ellos y de una correcta legislación va a depender ese estado de contento general tan necesarios para el buen desenvolvimiento del gobierno y para la propia felicidad individual ${ }^{57}$. Su visión no es, por tanto, únicamente la de un hombre que objetivamente informa al gobierno sobre las medidas que deben realizarse. La Memoria recoge también las apreciaciones de un autor que reflexiona en voz alta sobre la estrecha vinculación que debe existir entre la tarea de gobernar y una filosofia existencial basada en el "amor público». El estado debe promover la felicidad terrenal del hombre, mediante unas precisas directrices, que en Jovellanos pertenecen claramente al pensamiento ilustrado. Su punto de vista concuerda con el de aquellos que en su tiempo defienden las diversiones públicas como expresión de una concepción no sacralizada del estado, y en la que estas diversiones no son intrínsecamente perniciosas, a pesar del rechazo explícito del autor de los toros y los autos sacramentales ${ }^{58}$. Por el contrario, los entretenimientos públicos son beneficiosos para el individuo, y por tanto deben ser procurados por el estado.

El autor realiza su defensa de estas diversiones desde una perspectiva humanista, basándose en la necesidad que siente el hombre de alegrar su espíritu, si bien esta situación de bienestar individual repercute favorablemente en la evolución colectiva del gobierno ${ }^{59}$. Su óptica es la de un buen

en función de la Nación, haciendo de ella una gran personificación que subyace en la mayoria de las obras de este siglo. El autor establece un estrecho vínculo entre el bienestar personal y el colectivo, como si todos los miembros de la sociedad formasen parte de un solo cuerpo, que es el de la Nación.

${ }^{57}$ El concepto de felicidad parece estar unido en Jovellanos a un estado de autorrealización personal al que deben contribuir los distintos organismos con repercusión en la vida pública. Asi parece indicarlo también el autor en su discurso de 1781, dirigido a la Sociedad de Amigos del Pais de Asturias, titulado Sobre los medios de promover la felicidad de aquel Principado. En este caso, la idea de felicidad no está vinculada a la necesidad de las diversiones en la vida pública, sino al concepto útil de la ciencia. En ambos aspectos, Jovellanos expresa opiniones de gran modernidad, que aún hoy podrian ser aplicables a la sociedad española.

${ }_{9 \pi}$ La concepción del estado no vinculada a religión alguna expresada por Jovellanos en esta obra, así como su defensa de la diversión pública, ratifican una vez más la abierta mentalidad del autor, que, a pesar de la ecuanimidad que le caracteriza, defiende posiciones molestas para ciertos sectores del país apegados a antiguos privilegios, lo que le valió el destierro y encarcelamiento durante varios años. Sobre otro aspecto de la modernidad de su pensamiento, ver J. A. DOERING, «Un precursor español de las ideas modernas sobre el desarrollo de la agricultura: Gaspar Melchor de Jovellanos", Folia Humanistica, 1965, pp. 631-39.

${ }_{59}$ Las medidas solicitadas por Jovellanos parecen tener como fondo una especial preocupación por el individuo. Este aspecto da un toque de peculiaridad a su obra, ya que las soluciones colectivas que propone no son sino la proyección de esa preocupación existencial, que se refleja incluso en el tipo de lecturas al que era propenso. Sobre este aspecto, ver Edith HELMAN, «El humanismo de Jovellanos», 1961, incluido en Jovellanos y Goya, op. cit., pp. 7190; y H. L. DowDLE, The Humanitarism of Gaspar Melchor de Jovellanos, Universidad de Stanford 1954. 
conocedor del corazón humano, que quiere encauzar esta preocupación a través de las vías de que dispone el estado. Las leyes son para Jovellanos el vehículo idóneo para materializar estos objetivos, de ahí el lugar preferente que ocupan en su concepción vital. La relación del origen e historia de los espectáculos públicos que hace en esta obra está basada fundamentalmente en las distintas leyes que sobre estos aspectos han sido promulgadas, mientras en otra de sus creaciones más importantes, El delincuente honrado, plantea un problema semejante, la contribución de la ley a la felicidad humana, o por el contrario, su activa participación en su desgracia $^{60}$.

Esta Memoria muestra a un Jovellanos sensible al sufrimiento humano y a su antídoto, la diversión pública, en la que reconoce la estética de su factura cuando la posee. A pesar de la frialdad que pudiera encerrar un escrito de esta naturaleza, la sensibilidad del autor se deja entrever, de forma que podemos conocer sus sentimientos a través de unas páginas tan aparentemente distantes como podrían ser las de esta obra. Jovellanos se entusiasma por la magnificencia de los espectáculos medievales, por la belleza e inocencia de las diversiones del pueblo trabajador, y por la necesidad de unos espectáculos para la nobleza acordes con la aristocracia de su clase. Rechaza la mediocridad desde un punto de vista estético, del mismo modo que la desecha desde una perspectiva moral y cívica ${ }^{61}$. Su espíritu se deja ver entre los datos objetivos de esta Memoria, que además de mostrar al pensador inquieto por las tareas del buen gobierno, nos lleva al escritor sensible ante la belleza y el dolor humano que vibrará ante la naturaleza en creaciones posteriores $^{62}$. La intensidad con que reclama el arreglo de los espectáculos públicos en España parece obedecer más a esta sensibilidad, que a los proyectos ilustrados que quiere defender ${ }^{63}$. En Gaspar Melchor

${ }^{60}$ Sobre esta obra, ver J. SARrailh, «A propos du Delincuente honrado de Jovellanos», Mélanges d'Etudes portugaises offerts a M. George Le Gentil, 1949, pp. 337-51.

${ }^{61}$ Angel DEL Río en la citada «Introducción» señala esta característica de Jovellanos. "Este aristocratismo suyo, rasgo esencial de los hombres que presidian el llamado despotismo ilustrado, nos da una de las claves de su compleja personalidad, porque para él aristocracia no significaba abuso de privilegio, sino responsabilidad y servicio, necesidad de actuar en la vida según una elevada norma de valores morales», op. cit., p.12.

${ }_{62}$ Sobre este punto, ver J. CASO GONZÁleZ, «El castillo de Bellver y el prerromanticismo de Jovellanos», Homenaje a la Memoria de Rodríguez-Moñino, Madrid 1975; G. DiEGo, «Jovellanos y el paisaje», Sí, 6 de enero de 1944; y Ángel DEL Rio, «El sentimiento de la naturaleza en los Diarios de Jovellanos», Nueva Revista de Filología Hispánica, VII, 1953, pp. 630-37.

${ }^{63}$ Aunque el siglo XVIII, como afirma Américo CASTro, "es época de crítica y de lucha intelectual (...) en que el temperamento del escritor se esconde bajo el ejercicio del intelecto" («Algunos aspectos del siglo XVIII», Españoles al margen, Madrid 1973, pp. 52-56), en Jovellanos estos atisbos de sensibilidad, han llevado a varios críticos a calificarlo de prerromántico (sobre este aspecto ver J. ARCE FERNÁNDEZ, «Jovellanos y la sensibilidad prerromántica», Boletín de la Biblioteca Menéndez Pelayo, XXXVI, 1960, pp. 139-77). En la Memoria sobre los espectáculos, la exaltación del mundo medieval frente a la sociedad de su tiempo y la comprensión 
de Jovellanos tanto su actuación vital como el contenido de sus principales producciones están teñidas de esta especial vehemencia, propia de un espíritu apasionado que intentó hacer de la Ilustración el cauce apropiado para manifestarse.

del sufrimiento humano dan un toque de originalidad a esta obra, en la que el escritor se mueve no exclusivamente por condicionamientos ideológicos de carácter ilustrado. 